\title{
Texture and Cleavage in Molybdenum
}

\author{
P. I. WELCH† and G. J. DAVIES $\ddagger$ \\ †Institut fur Metallkunde der T. U. Clausthal, Grosser Bruch 23, D-3392 \\ Clausthal-Zellerfeld, F.R.G. \\ $\ddagger$ Department of Metallurgy, University of Sheffield, Mappin Street, Shef- \\ field, U.K.
}

(Received December 6, 1982)

\begin{abstract}
It is of considerable technological importance to establish how far textures introduced into controlled-rolled steels by finish rolling at low temperatures may affect the fracture strength. The purely textural effect is difficult to isolate in such steels because of anisotropy associated with grain shape, inclusions and pearlite banding. Consequently, an investigation was carried out using molybdenum, a b.c.c. single phase material showing good structural homogeneity, as a model. Texture development was studied using crystallite orientation distribution function analysis to identify a suitable processing route leading to a sharp texture with a suitable distribution of $\{100\}$ cleavage planes. The behaviour of a sharply textured specimen was analysed by taking fracture specimens from various orientations in the plate. The energy absorbed in impact showed a positive correlation with the density of 100 planes in the crack direction, but the extent of the variation was less than would have been expected had crack propagation been the controlling step in the fracture process.
\end{abstract}

\section{INTRODUCTION}

Early work with molybdenum (Ransley and Rooksby, 1938; Semchysen and Timmons, 1952) showed that the development of a strong $\{100\}\langle 011\rangle$ texture leads to a reduction in the fracture strength of specimens tested with their axes at $45^{\circ}$ to the rolling direction (that is, with their axes parallel to the cleavage plane normal). This is compatible with the evidence from the work of Allen et al. (1956) that $\{100\}$ is the preferred cleavage plane in b.c.c. metals. Subsequently, Webster et al. (1971) reported a considerable effect of preferred orienta- 
tion on the low-temperature tensile behaviour of polycrystalline rimmed steel and silicon-iron. They obtained results which showed some significant texture dependence of the fracture behaviour. The anisotropy of the cleavage fracture stress showed a degree of dependence on the distribution of cleavage plane normals. However, for neither the molybdenum nor the steels were rigorous quantitative measurements of the texture and distribution of $\{100\}$ plane normals made. Recent work (Mintz et al., 1976; Mintz et al., 1979) with controlled-rolled steels in which impact fracture results were correlated with texture, using crystallite orientation distribution function (c.o.d.f.) procedures, showed some correlations for through-thickness tests but not for in-plate tests. In this case, however, matters were complicated by microstructural anisotropy associated with pearlite banding and inclusions. On the other hand, work by Inagaki et al. (1977) which also involved controlled rolled steels yielded evidence for a qualitative correlation between texture and in-plate fracture strength.

It is clear that it is of considerable commercial importance to establish whether or not the textures introduced into ferrite by finishing controlled-rolled steels at temperatures below the $\gamma$-phase boundary could contribute to low fracture strength. To do this it is necessary to isolate, as far as possible, textural effects from microstructural effects. To examine textural effects alone, the study of molybdenum, a single phase b.c.c. material with good structural homogeneity, was undertaken. Initially it was necessary, however, to carry out a study of texture development in molybdenum in order to identify a processing route which would give a distribution of $\{100\}$ cleavage planes which could be effectively utilised.

\section{EXPERIMENTAL}

\subsection{Material}

Experiments were carried out on hot-rolled molybdenum slab, $25 \mathrm{~mm}$ thick, and of 99.9 per cent purity. The slab was annealed for 3 hours at $800^{\circ} \mathrm{C}$ prior to further rolling. All rolling was carried out on a 2-high rolling mill with $200 \mathrm{~mm}$ diameter work rolls at a speed of $0.16 \mathrm{~m} \mathrm{sec}^{-1}$. Problems were initially encountered with "crocodiling" of the material i.e. cracking along the central section parallel to the rolling plane, on exit from the rolls. As a result slab sections were premachined with wedge-shaped ends prior to rolling to overcome these difficulties as 


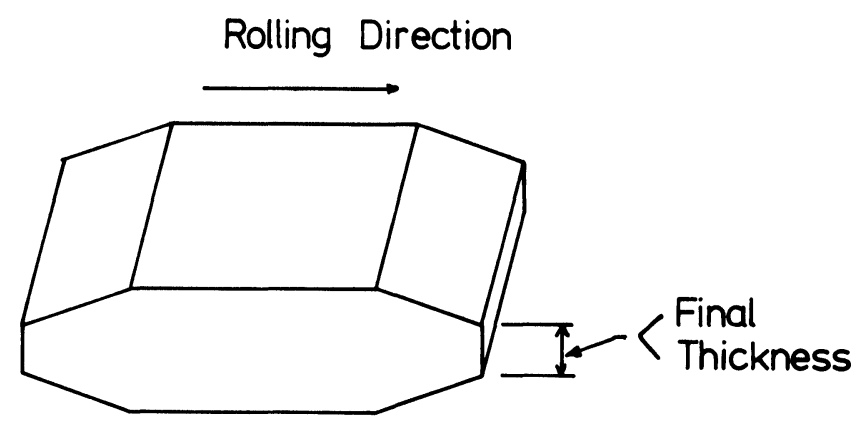

FIGURE 1 Configuration of billet before rolling necessary to avoid crocodiling during rolling.

shown in Figure 1. Only the central section of the slab, which had received the required deformation was used for the preparation of fracture specimens. Both direct reduction and cross-rolling were performed at a temperature of $700^{\circ} \mathrm{C}$ (warm-rolling) with a reduction of $0.25 \mathrm{~mm}$ per pass. The material was reversed and inverted between passes so as to produce orthotropic rolling symmetry. All annealing operations were carried out under vacuum.

\subsection{Texture determination}

Texture measurements were carried out on a Siemens texture goniometer using the back-reflection technique (Schulz, 1949) and composite specimens (Welch, 1980). $\{110\},\{200\}$ and $\{211\}$ pole figures were determined and used to derive the crystallite orientation distribution function, $w(\phi, \theta, \psi)$ (Roe, 1965; Bunge, 1965) expanded to the 20th order. Plots of the orientation distribution function are presented as constant$\phi$ sections of Euler space. In these plots the contour with the value unity (equivalent to the intensity from a random specimen) is shown as a broken line. Where necessary indexing of regions of these plots was carried out using published charts (Davies et al., 1971). The volume fractions of crystallites with $\{100\}$ cleavage planes oriented within $5^{\circ}$ of any chosen direction in the plane of the plate were determined by integration over the appropriate volume of Euler space (Kallend and Davies, 1969). This procedure provides quantitative accuracy not able to be achieved through equivalent measurements on $\{200\}$ pole figures. 


\subsection{Mechanical testing}

$25 \mathrm{~mm}$ thick molybdenum plate was cross-rolled by $70 \%$ to give a plate $8.5 \mathrm{~mm}$ thick, and annealed for 30 minutes at $1200^{\circ} \mathrm{C}$. Round specimens of $8 \mathrm{~mm}$ diameter were machined from the plate with their axes at $0^{\circ}$, $22.5^{\circ}, 45^{\circ}, 67.5^{\circ}$, and $90^{\circ}$, to the rolling direction of the plate. Hounsfield $\mathrm{V}$ notches were cut into these, parallel to the normal direction in the plate. The crack propagation direction was thus fixed in the plane of the plate in the required direction. These specimens were tested in a Franck mini impact tester and values determined for the energy absorbed in impact. Six specimens of each orientation were tested.

\section{RESULTS AND DISCUSSION}

\subsection{Hot-rolling texture}

The crystallite orientation distribution function (c.o.d.f.) plot for the as-received, hot-rolled material is given in Figure 2. In this, and subsequent figures, the texture severity is a measure of the standard
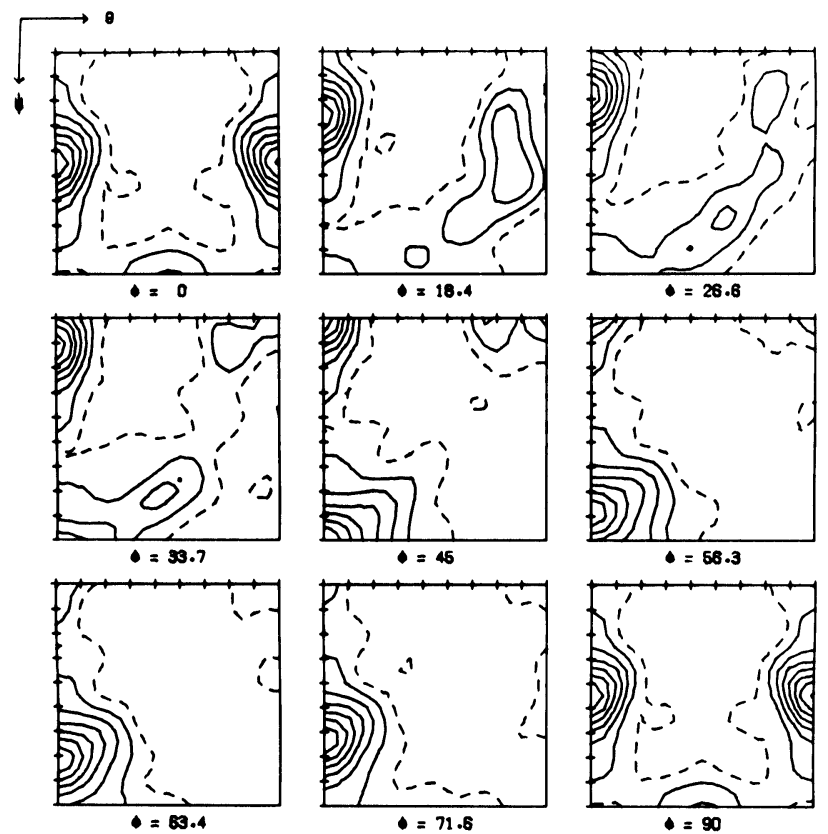

FIGURE 2 The c.o.d.f. for molybdenum as received in the hot-rolled condition. Contour intervals 0.5 times random. Texture severity 0.54 . 

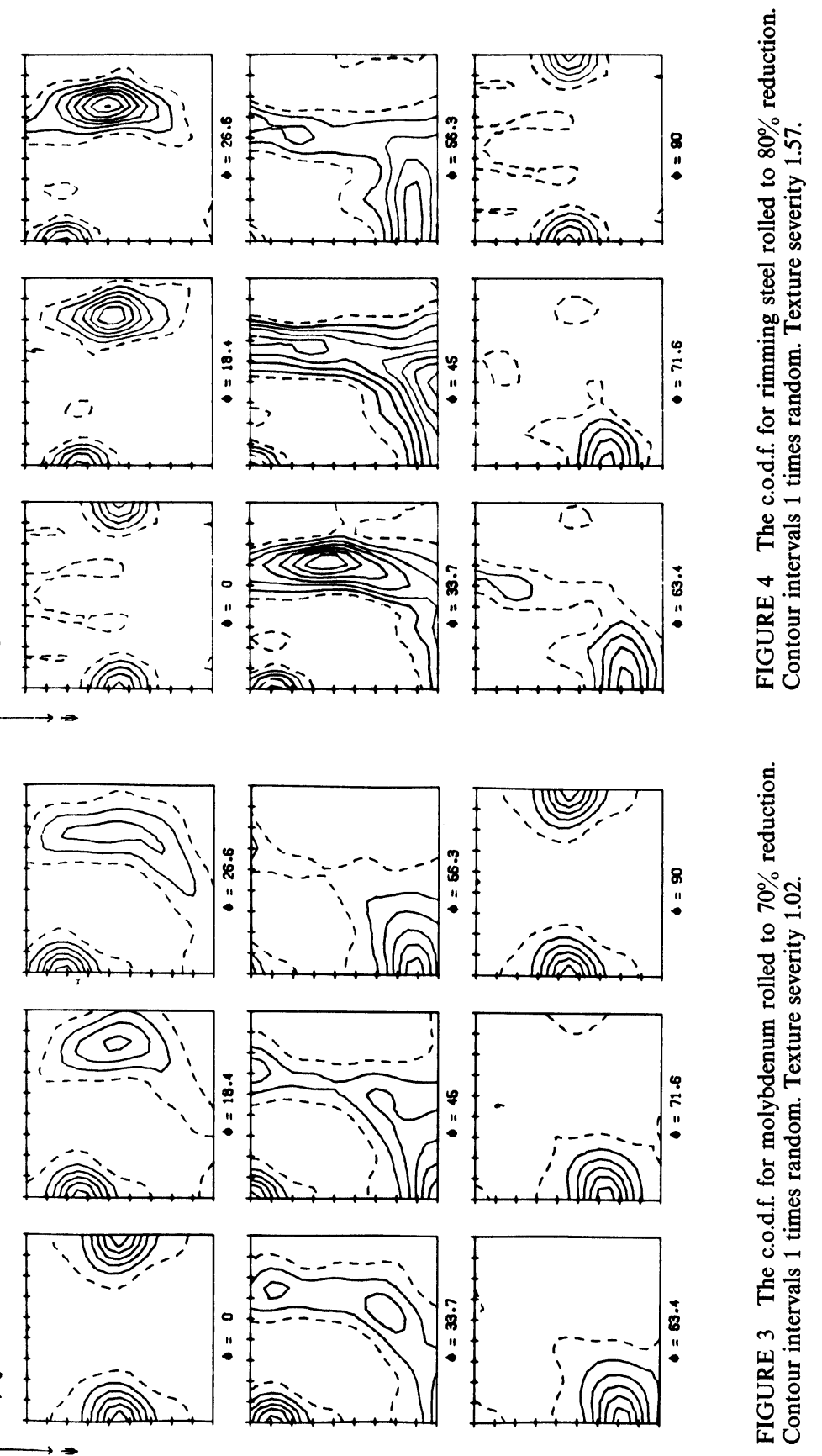


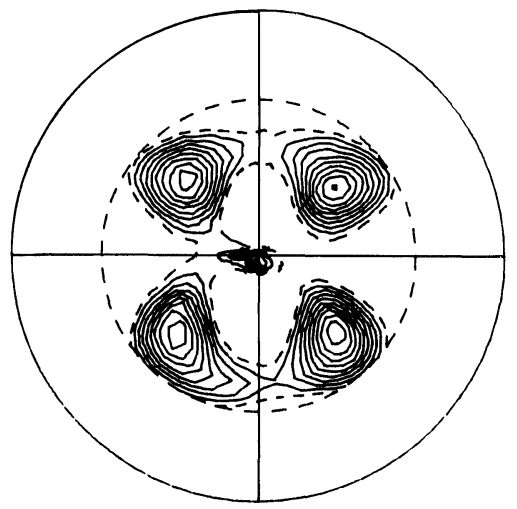

a

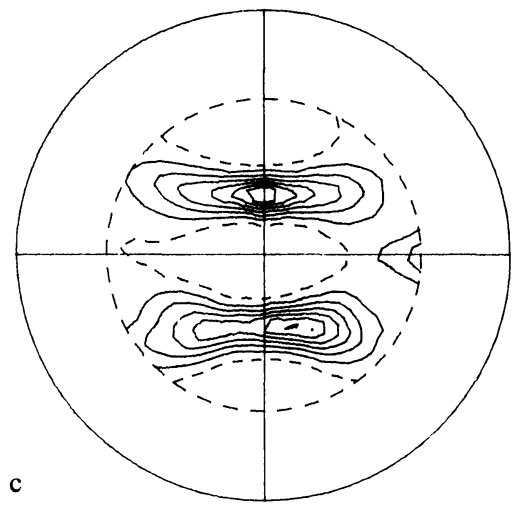

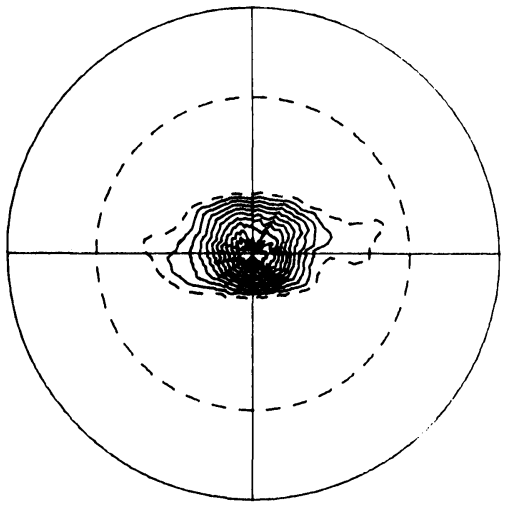

b

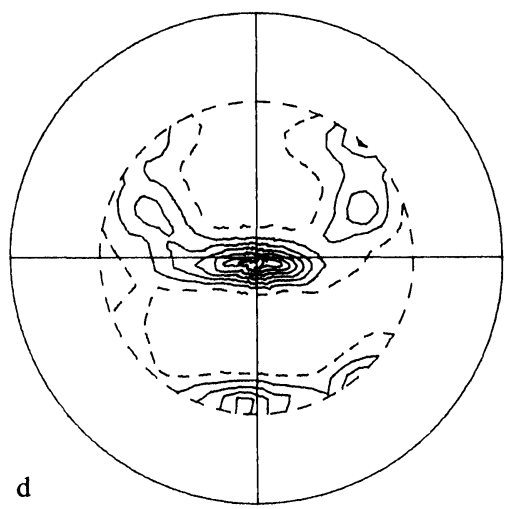

FIGURE 5 Pole figures from through-thickness locations.

a) $\{110\}$.

b) $\{200\}$, from surface layer, contour intervals (a) 1.0 to 1.9 by 1.0 (b) 1.0 to 3.0 by 0.2 .

c) $\{110\}$.

d) $\{200\}$, from one-third depth, contour intervals (c) 1.0 to 4.0 by 0.5 (d) 1.0 to 4.5 by 0.5 .

deviation of the c.o.d.f. from that of a random sample. The texture was similar to that previously reported for hot-rolled steels (Goodwill, 1972) but a good deal more severe. The texture was best described as a tube of orientations centred on $\{100\}\langle 011\rangle$ with a minor $\{110\}\langle 001\rangle$ component.

\subsection{Warm-rolling textures}

The c.o.d.f. for $70 \%$ warm rolled molybdenum is given in Figure 3. The 

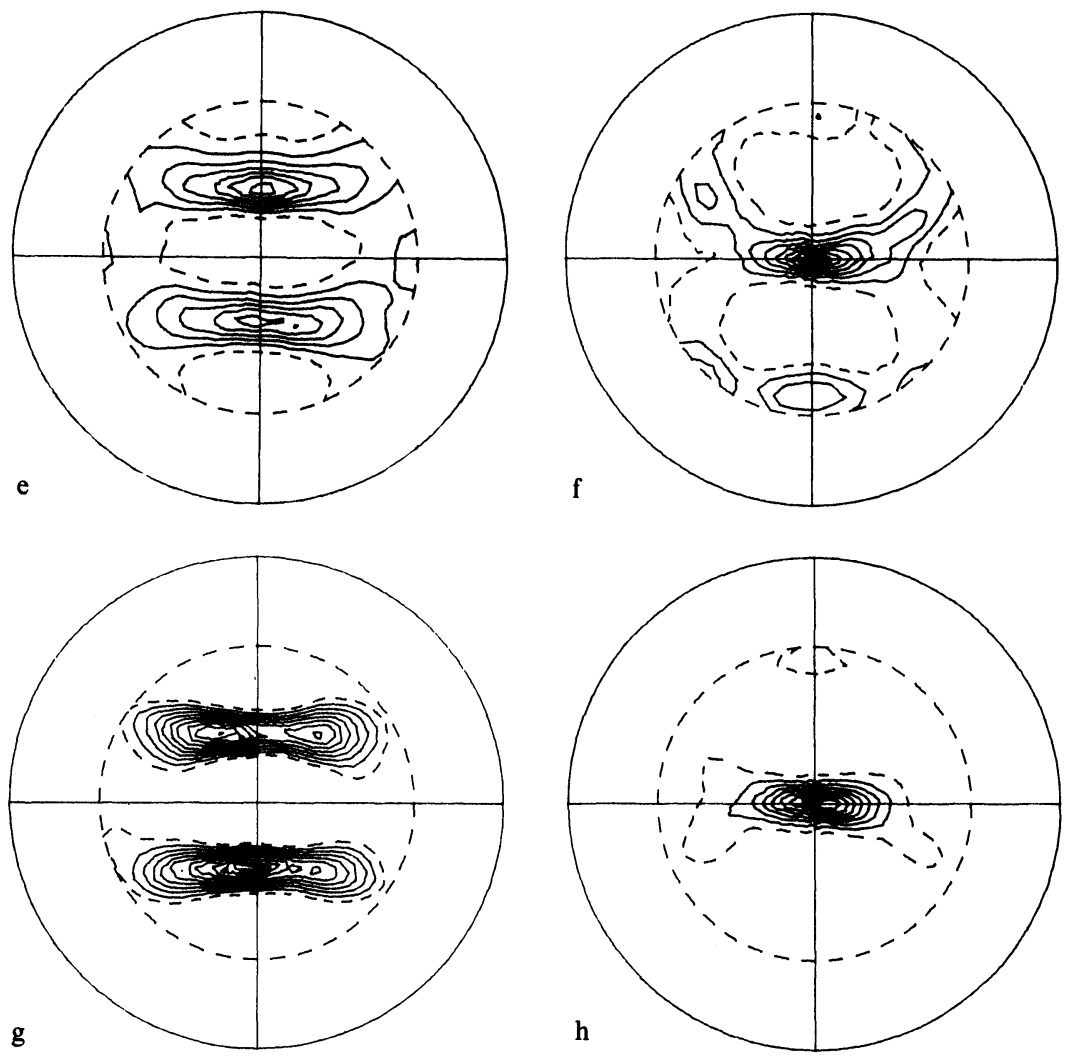

e) $\{110\}$

f) $\{200\}$, from two-third depth, contour intervals (c) 1.0 to 4.0 by 0.5 (f) 1.0 to 4.5 by 0.5 .

g) $\{110\}$.

h) $\{200\}$, from centre plane, contour intervals (g) 1.0 to 3.0 by 0.2 (h) 1.0 to 4.5 by 0.5 .

direct-rolled specimens had a starting thickness of $10 \mathrm{~mm}$ and were rolled to a thickness of $2.7 \mathrm{~mm}$. The c.o.d.f. is very similar to that of rimming steel after a similar reduction. A c.o.d.f. for rimming steel, cold rolled $80 \%$ is given in Figure 4 for comparison. Both textures are comprised of a tube of orientations running from $\{100\}\langle 011\rangle$ to $\{11118\}\langle 44 \overline{11}\rangle$ and a partial $\{111\}\langle u v w\rangle$ fibre texture. The difference lies in the distribution within these components. In the molybdenum there is a maximum at $\{100\}\langle 011\rangle$ and a rather weak $\{111\}\langle u v w\rangle$ 
fibre texture. The $\{110\}\langle 001\rangle$ component present in the hot-rolled material has disappeared. The steel shows a peak at $\{112\}\langle 1 \overline{1} 0\rangle$ and a strong $\{111\}\langle u v w\rangle$ texture. These textural data are broadly in agreement with those reported from previous pole figure studies (Ransley and Rooksby, 1938; Custers and Riersma, 1946; Semchysen and Timmons, 1952). The c.o.d.f. is in agreement with that predicted by simulation assuming multiple slip on $\{110\}\langle 1 \overline{1} 1\rangle$ systems (Kallend, 1971).

\subsection{Through-thickness texture variations}

Direct pole figures were determined at various levels through the specimen thickness on rolled specimens. The finished thickness was $2.7 \mathrm{~mm}$ and measurements were made on the surface, at $0.5 \mathrm{~mm}$ and $1.0 \mathrm{~mm}$ below the surface and on the centre section. $\{110\}$ and $\{200\}$ pole figures are shown in Figure 5. Figure 6 shows positions of important ideal orientations in these $\{100\}$ and $\{200\}$ pole figures, superimposed on the pole figures for the composite specimen.
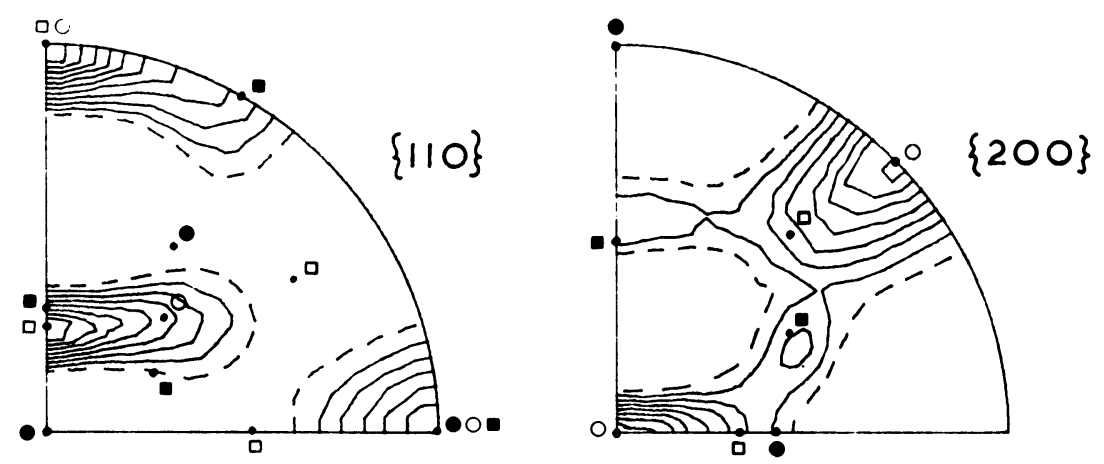

FIGURE 6 Ideal orientations for pole figures superimposed on polefigures for $70 \%$ direct rolled specimen. Contour intervals (a) 1.0 to 3.0 by 0.2 (b) 1.0 to 2.4 by 0.2 .

$$
\begin{array}{ll}
\bigcirc\{100\}\langle 011\rangle & \mathbf{a}\{111\}\langle 112\rangle \\
\square\{112\}\langle 110\rangle & \square
\end{array}
$$

The texture of the surface layer is composed entirely of the $\{100\}$ $\langle 011\rangle$ component. This is a single texture but is rather weak overall. The level of the $\{100\}\langle 011\rangle$ component is approximately the same as in the c.o.d.f. The first and second sub-surface layers show textures that are very similar to each other and to the bulk of the material. The central section shows a texture similar to that of the bulk with the $\{100\}\langle 011\rangle$ 
component at about the same level of intensity but with the $\{112\}\langle 1 \overline{10}\rangle$ component reduced.

The variation of the texture of molybdenum as a function of depth through the thickness is similar to that reported by Vandemeer and coworkers $(1970,1977)$ in niobium and a niobium-vanadium alloy. The immediate surface layer has a $\{100\}\langle 011\rangle$ component similar in severity to the bulk material but is devoid of other $\{h k l\}\langle 110\rangle$ orientations. A similar absence of $\{112\}\langle 1 \overline{10}\rangle$ can also occur in other positions in the plate depending on the exact deformation geometry.

The observed dependence of the texture on depth was not considered sufficiently severe to affect the analysis of fracture behaviour.

\subsection{Cross-rolling texture of molybdenum}

The c.o.d.f. for $70 \%$ cross-rolled molybdenum is given in Figure 7 . The texture is best described as a combination of two orientation tubes. The normal b.c.c. cold-rolling tube, running from $\{100\}\langle 011\rangle$ to $\left\{\begin{array}{lll}11 & 11 & 8\end{array}\right\}$ $\langle 44 \overline{11}\rangle$ is present with a distinct maximum centred on the $\{100\}\langle 011\rangle$ orientation. The second tube is centred on $\{110\}\langle 001\rangle$ and is somewhat weaker. Previous workers (Ransley and Rooksby, 1938; Custers and Riersma, 1946; Semchysen and Timmons, 1956) have reported that cross-rolling produces a sharpening of the ideal orientation $\{100\}\langle 011\rangle$ and introduces a further spread of orientations along $\{111\}\langle u v w\rangle$, and centred on $\{111\}\langle 11 \overline{2}\rangle$. A prediction based on equal amounts of straight and transverse rolling and assuming $\{110\}\langle 111\rangle$ multiple slip (Taylor, 1938; Bishop and Hill, 1952) for a total deformation of $50 \%$ gives rise to the c.o.d.f. shown in Figure 8. This predicts peaks at $\{100\}\langle 011\rangle$ orientations and a well developed $\{111\}\langle u v w\rangle$ fibre texture. There are no $\{110\}\langle 001\rangle$ components in the prediction.

The presence of the $\{110\}\langle 001\rangle$ orientation is most probably a result of shearing during the rolling process. The component has been previously identified (Nussbaum and Brenner, 1955; Hoddinott and Davies, 1972) as arising from shear deformation in the surface layers of hot-rolled sheet steels. The absence of this component from the directly-rolled material is almost certainly a result of the different deformation geometry resulting from the smaller initial thickness and the greater cooling in the thinner material during the rolling process. The presence of this component in the starting material supports this. Morris (1976) has observed this texture as a weak component in some controlled-rolled steels. 

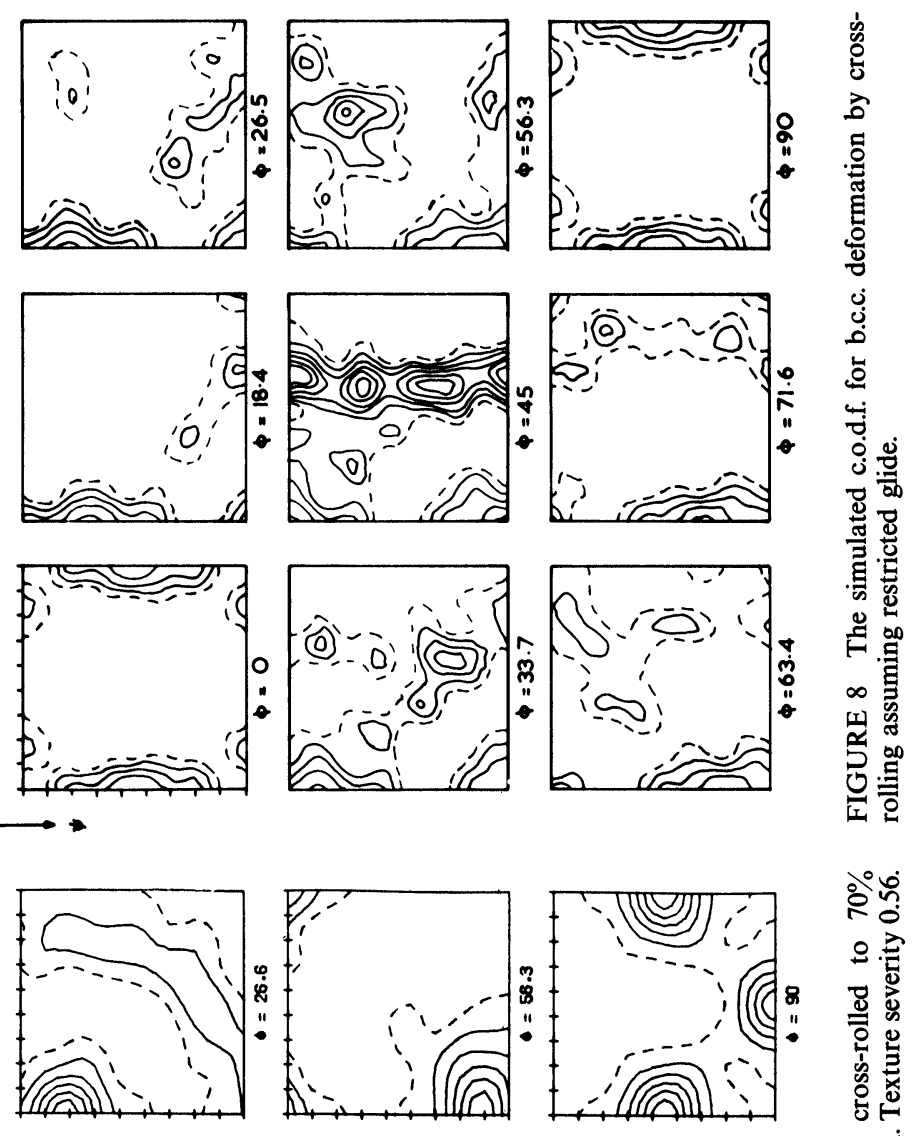

ถำ

오률

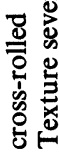
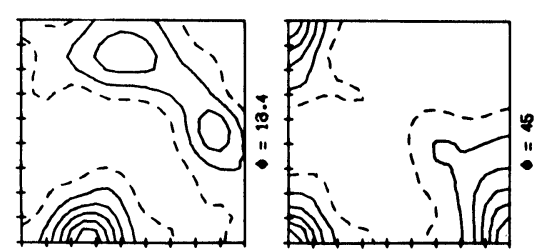

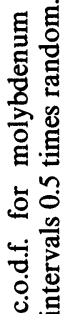
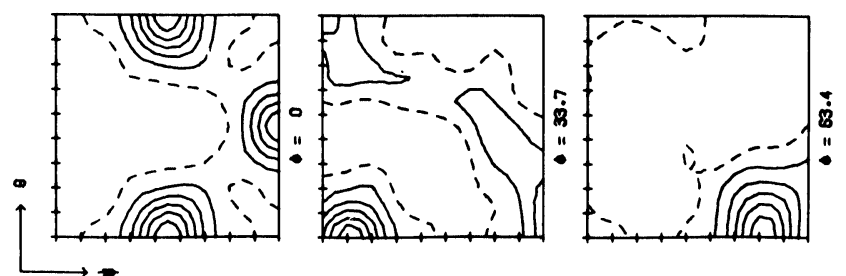

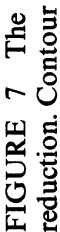


A simulation of the texture development assuming $\{110\}\langle 1 \overline{1} 1\rangle$ glide predicted the $\{110\}\langle 001\rangle$ texture as the main component when the simulation was carried out using a strain tensor composed of equal amounts of plane strain and alternate $+\mathrm{ve} /-$ ve shear. A strain state of this type was found also to predict the textures occurring in aluminium-magnesium alloys under conditions of high friction (Welch, 1976) and seems to be representative of the rolling of thick sections with rough rolls.

The behaviour of the b.c.c. cold-rolling tube is consistent with the prediction. There is a tendency for localisation at the $\{100\}\langle 011\rangle$ orientation. The reduced intensity of this orientation as compared to the direct-rolled material can be attributed to the presence of the shear component. The presence of shear components has been shown to reduce the intensity of normal rolling components in f.c.c. metals (Welch, 1976). Dynamic recovery at the higher internal temperature of the thicker plate could also make a contribution.

The absence of a $\{111\}\langle u v w\rangle$ component is somewhat unexpected. The component is present in the direct-rolled material, although at a very much lower intensity than the steel specimen. The appearance of the component has also been reported previously in cross-rolled molybdenum although in very much thinner sheets and using photographic texture determination methods. Morris (1976) has shown that this component is found in the centre of controlled-rolled steels. Dynamic recovery in the absence of niobium and differences in slip behaviour may result in its absence in the present case.

\subsection{Annealing textures of $70 \%$ direct-rolled molybdenum}

C.o.d.f.'s for direct rolled molybdenum annealed for 30 minutes at $1200^{\circ} \mathrm{C}$ and $1500^{\circ} \mathrm{C}$ are shown in Figures 9 and 10 , respectively. The texture after annealing at $1200^{\circ} \mathrm{C}$ shows remnants of the $\{100\}\langle 011\rangle$ texture component and the $\{111\}\langle u v w\rangle$ component (now centered on $\{111\}\langle 0 \overline{1} 1\rangle)$. There are also minor cube-texture components and other near cube components. On annealing at $1500^{\circ} \mathrm{C}$ the remnants of the cold-rolling texture completely disappear and the other components consolidate into near-cube components.

The overall intensity levels are low and the texture approximates to a random texture. Photographic methods used in earlier investigations would have been unable to resolve the individual peaks and the random textures reported there are consistent with the present results. 

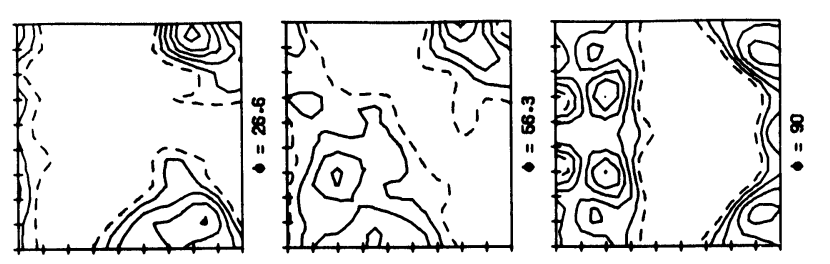

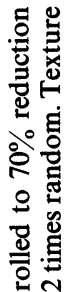
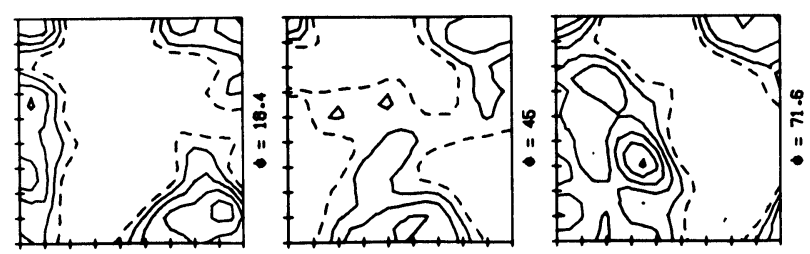

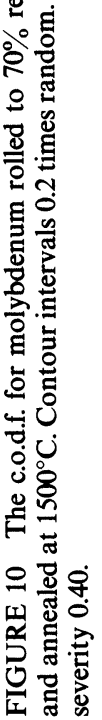
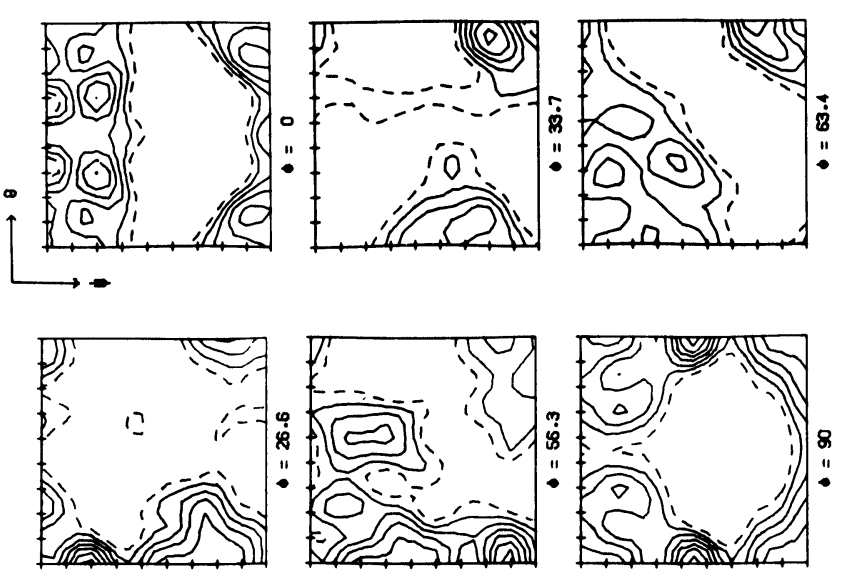

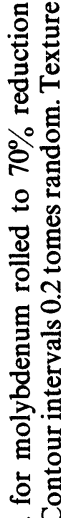
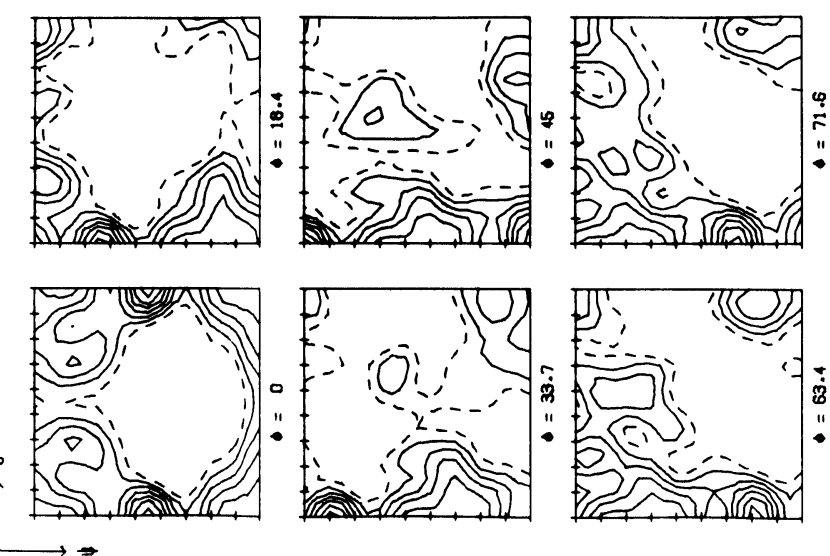

نัن

ن용

틀

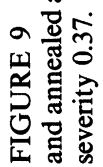



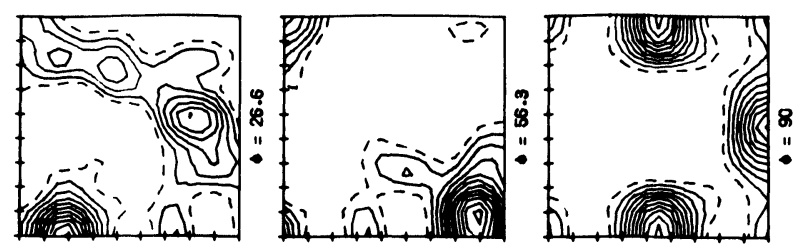

ફे.

우

웅

离
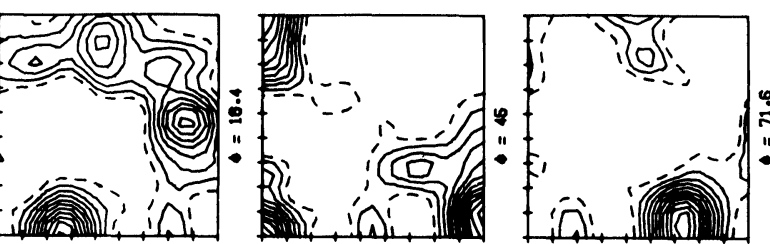

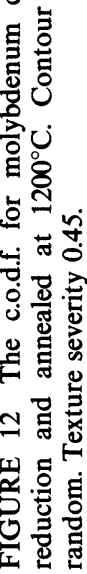

$\infty$
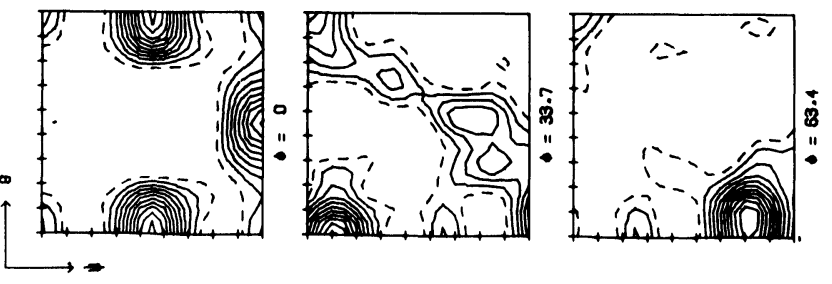

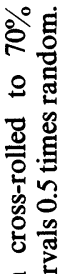
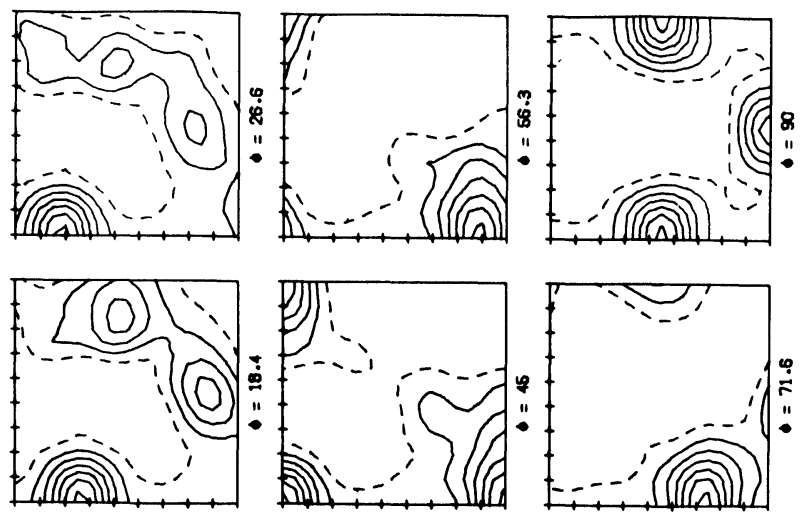

톨.

흥

층용

눙

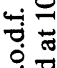
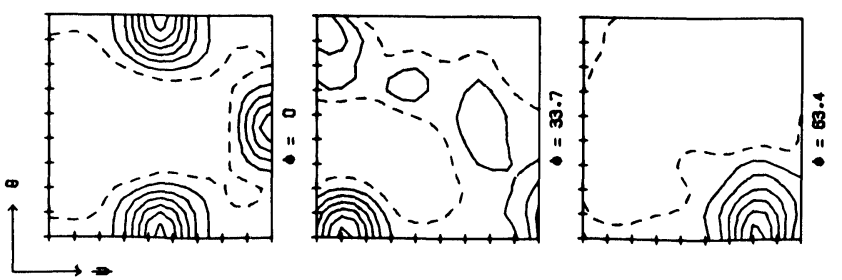

ن

๖

- 츨

二 ত్

드

両运 

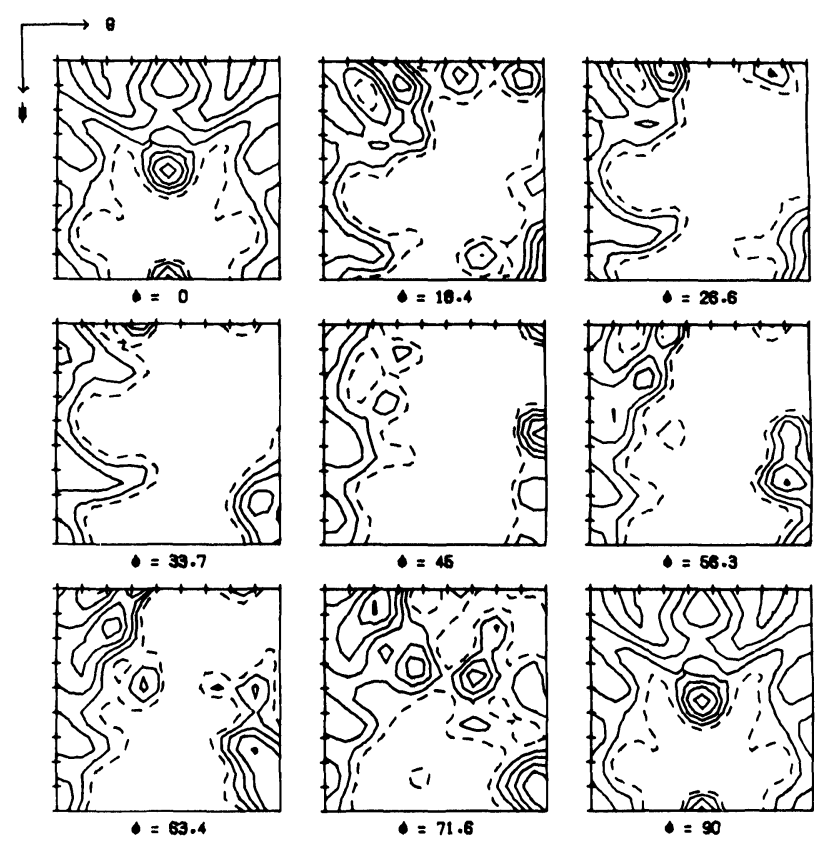

FIGURE 13 The c.o.d.f. for molybdenum cross-rolled to $70 \%$ reduction and annealed at $1500^{\circ} \mathrm{C}$. Contour intervals 0.2 times random. Texture severity 0.34 .

The annealing texture at $1200^{\circ} \mathrm{C}$ is very similar to that for a $\mathrm{Fe} / 1 \% \mathrm{Mn}$ alloy rolled in the $\gamma$-region and air cooled (Welch and Mintz, 1978).

\subsection{Annealing textures of $70 \%$ cross-rolled molybdenum}

C.o.d.f.'s for $70 \%$ cross-rolled molybdenum annealed for 30 minutes at $1000^{\circ} \mathrm{C}, 1200^{\circ} \mathrm{C}$ and $1500^{\circ} \mathrm{C}$ are given in Figures 11,12 and 13 , respectively. The texture of the material annealed at $1000^{\circ} \mathrm{C}$ shows an almost identical texture to the cold rolled case but the severity had increased slightly. This increase is normal during the initial stages of recovery (Welch, 1976). Annealing at $1200^{\circ} \mathrm{C}$ leads to a diminution of the texture, with no change of orientation, and the concurrent appearance of a mild cube texture. After annealing at $1500^{\circ} \mathrm{C}$ the texture has declined significantly in severity, the rolling components having disappeared, apart from a minor $\{110\}\langle 001\rangle$ component. This texture is similar to that of the directly-rolled and annealed sample for the same 
temperature, being comprised of irrational, near-cube orientations. There is a fairly strong $\{110\}\langle 1 \overline{1} 1\rangle$ component which does not appear in the directly-rolled and annealed sample.

\subsection{The correlation of the distribution of cleavage plane normals and impact strength}

As a result of the previous work the sample cross-rolled $70 \%$ and annealed at $1000^{\circ} \mathrm{C}$ (Figure 11) was used to examine the effect of the distribution of $\{100\}$ cleavage planes on impact strength. The c.o.d.f. from the plate was integrated to determine the volume fraction of crystallites with $\{100\}$ planes lying parallel to the crack propagation direction for each specimen. These values, in multiples of that for a random sample, are given in Table 1.

TABLE 1

Volume fractions of $\{100\}$ cleavage planes lying within $5^{\circ}$ of the crack propagation plane for impact specimens.

\begin{tabular}{cc}
\hline $\begin{array}{c}\text { Angle of specimen axis } \\
\text { to rolling direction }\end{array}$ & $\begin{array}{c}V_{f} \\
(x \text { random })\end{array}$ \\
\hline $0^{\circ}$ & 1.73 \\
$22.5^{\circ}$ & 1.03 \\
$45^{\circ}$ & 1.76 \\
$67.5^{\circ}$ & 0.81 \\
$90^{\circ}$ & 0.63 \\
\hline
\end{tabular}

The mean value of the energy absorbed in the impact fractures is shown plotted against $V_{f}$ from Table 1 in Figure 14. The error bars represent the standard deviation in the sets of six samples and show the necessity for multiple testing in such experiments. The data show a correlation between low fracture strength and high cleavage-plane density within $5^{\circ}$ of the fracture propagation plane. However, the overall differences in energy absorbed are small. The differences are, nevertheless, consistent with the textural data.

\section{CONCLUSIONS}

The variation in impact strength within the plate for cold rolled and annealed molybdenum is consistent with the variation in crystallographic anisotropy. The scale of the variation is less than would be 


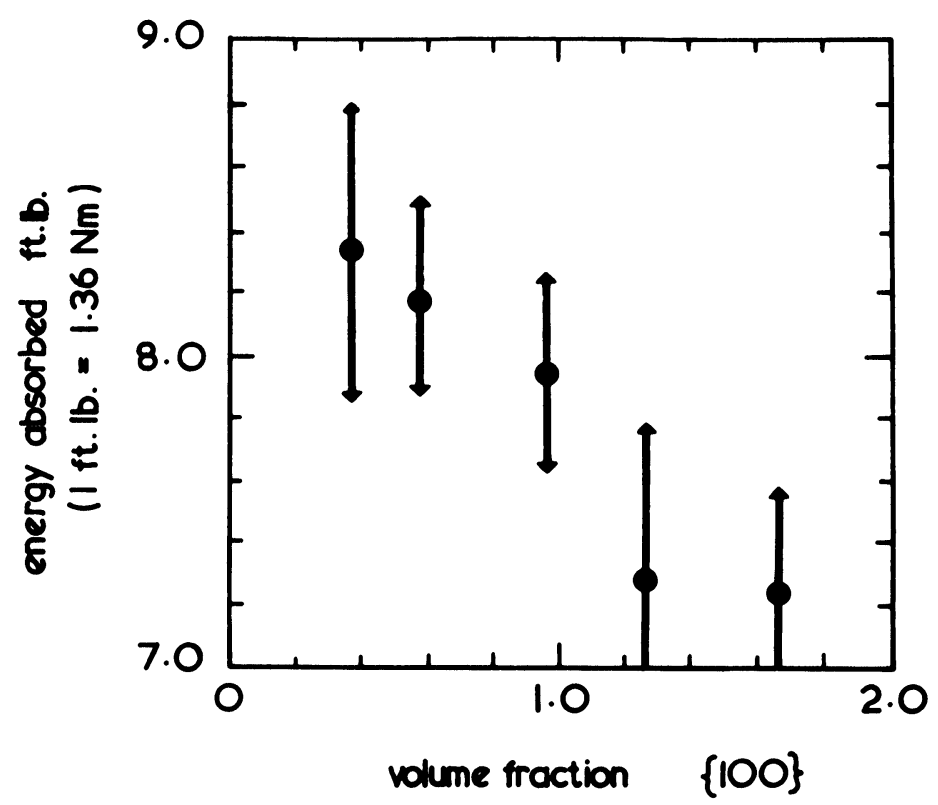

FIGURE 14 The correlation between absorbed fracture energy and density of cleavage planes parallel to crack propagation plane.

expected if propagation were the controlling step for cleavage fracture in molybdenum. There is evidence to suggest (Knott, 1973) that the crack-nucleation stage is most important in the cleavage of molybdenum. The use of pre-cracked slow-bend specimens tested at low temperatures might enable the purely textural effect to be isolated.

\section{Acknowledgements}

The work was carried out while the authors were in the Department of Metallurgy and Materials Science, University of Cambridge. The Science Research Council provided financial support (PIW) and this is gratefully acknowledged.

\section{References}

Allen, N. P., Hopkins, B. E. and McLennan, J. E. Proc. Roy. Soc. A234, 221-236 (1956).

Bishop, J. F. W. and Hill, R. Phil. Mag. 42, 414-427 and 1298-1307 (1952).

Bunge, H. J. Z. Metallke 56, 872-878 (1965).

Custers, J. F. H. and Riersma, J. C. Physica 12, 195-211 (1946).

Davies, G. J., Goodwill, D. J. and Kallend, J. S. J. Appl. Cryst. 4, 67-70 (1971).

Goodwill, D. J. Ph.D. thesis, University of Cambridge (1972).

Hoddinott, D. S. and Davies, G. J. J.I.S.I. 210, 624-628 (1972). 
Inagaki, H., Kurihara, K. and Kozasu, I. Trans. I.S.I.J. 17, 75-81 (1977).

Kallend, J. S. Ph.D. thesis, University of Cambridge (1971).

Kallend, J. S. and Davies, G. J. J. Inst. Met. 97, 350-352 (1969).

Knott, J. F. Fundamentals of Fracture Mechanics (Butterworths, London), pp. 188 et seq. (1973).

Mintz, B., Morrison, W. B., Morris, P. P. and Davies, G. J. Texture and the Properties of Materials (Metals Society, London), pp. 224-234 (1976).

Mintz, B., Morrison, W. B., Welch, P. I. and Davies, G. J. Textures of Materials (Springer-Verlag, Berlin), pp. 465-474 (1979).

Morris, P. P. Ph.D. thesis, University of Cambridge (1976).

Nussbaum, C. and Brenner, W. Trans. A.S.M. 47, 715-726 (1955).

Ransley, C. E. and Rooksby, H. P. J. Inst. Met. 62, 205-214 (1938).

Roe, R. J. J. Appl. Phys. 36, 2024-2031 (1965).

Schulz, L. G. J. Appl. Phys. 20, 1030-1033 (1949).

Semchyshen, M. and Timmons, G. A. Trans. A.I.M.M.E. 194, 279-286 (1952).

Taylor, G. I. J. Inst. Met. 62, 307-324 (1934).

Vandemeer, R. A. and Bernal, J. B. Texture 2, 183-203 (1977).

Vandemeer, R. A. and Ogle, J. C. Metall. Trans. 1, 1461-1463 (1970).

Webster, T. H., Smallman, R. E. and Dillamore, I. L. Metal Sci. J. 5, 68-73 and 74-80 (1971).

Welch, P. I. Ph.D. thesis, University of Cambridge (1976).

Welch, P. I. Texture 4, 99-110 (1980).

Welch, P. I. and Mintz, B. Unpublished research (1978). 